\title{
Commiphora mukul Prevents Myocardial Dysfunction in Streptozotocin Induced Diabetic Rats
}

\author{
Kalyani Barve* and Nima Bhonsle
}

SPP-School of Pharmacy and Technology Management, SVKM's NMIMS, Mumbai, India

\begin{abstract}
The objective of this study is to evaluate the effect of ethyl acetate extract of Commiphora mukul (guggul) (EACM) in streptozotocin (STZ) induced diabetic cardiomyopathy in rats. Diabetes was induced in rats with STZ (45 $\mathrm{mg} / \mathrm{kg}$, i.p). The animals were divided in four groups: I- normal control, II-diabetic control, III- diabetic animals treated with EACM $(400 \mathrm{mg} / \mathrm{kg} / \mathrm{day}$, p.o $)$ and IV- normal animals treated with EACM $(400 \mathrm{mg} / \mathrm{kg} / \mathrm{day}, p . o)$.Cardiomyopathy developed after eight weeks of induction of diabetes. The biochemical parameters (glucose, triglycerides, cholesterol, LDL, HDL, CKMB, LDH) were evaluated at regular intervals. The hemodynamic measurements (LVDEP, Mean BP, Max $\mathrm{dP} / \mathrm{dT}$, Min $\mathrm{dP} / \mathrm{dT}$, ST segment and QT interval) were done on the $8^{\text {th }}$ week. Standardized EACM contained $3.36 \% \mathrm{w} / \mathrm{w}$ of guggulsterones. There were significant changes observed in the biochemical, hemodynamic and histological parameters of diabetic animals indicating induction of diabetic cardiomyopathy, whereas diabetic animals treated with EACM for eight weeks showed significant improvement in these parameters which serve as diabetic and cardiac markers. The present study reveals that EACM is effective in preventing diabetes induced myocardial dysfunction. This might be due to its efficacy in (a) normalizing the metabolic disturbances by acting as Farnesoid X receptor antagonist (FXR) or PPAR-alpha and PPAR-gamma agonist thereby regulating the lipid and glucose metabolism, (b) having a cardioprotective effect through various mechanisms such as regulation of endothelial nitric oxide synthase (eNOS), angiotensin type 2 receptor expression etc or (c) both. Thus, guggul might be a promising candidate to be evaluated for clinical efficacy in diabetic patients for the prevention of cardiomyopathy.
\end{abstract}

Keywords: CK-MB, Commiphora mukul, dyslipidaemia, guggul, guggulsterones, hyperglycemia, LDH.

\section{INTRODUCTION}

Diabetes mellitus (DM) is the most common metabolic disorder currently affecting more than 180 million people around the world. According to the Diabetic Atlas published by the International Diabetes Federation (IDF) it has been estimated that the number will rise to 70 million by 2025 in India itself. Diabetes is associated with most known risk factors for cardiac failure [1]. The prevalence of diabetes is rapidly rising all over the globe at an alarming rate [2]. Type I diabetes (T1D) is one of the most common autoimmune diseases, where auto-aggressive $\mathrm{T}$ cells infiltrate the islets of Langerhans in the pancreas and play an important role by specifically destroying the insulin producing beta-cell population [3]. The pathogenesis of type II diabetes (T2D) is multifactorial and complex, resulting from insulin resistance in the liver, adipose tissue and skeletal muscles, impairment of pancreatic insulin secretion, and unrestrained hepatic glucose production [4].

Cardiovascular disease remains the leading cause of mortality and morbidity in individuals with diabetes. The rate of infarction is several-fold higher in the diabetic population, due to the high rates of thrombosis [5]. Diabetes mellitus can also affect cardiac structure and function in the absence of

*Address correspondence to this author at the SPP School of Pharmacy and technology management, SVKM's NMIMS, Vile Parle (West), Mumbai 400056, India; Tel: 9920467646; Fax: 022-26185422;

E-mail: barve.kalyani@gmail.com established risk factors such as hypertension, coronary artery disease (CAD), atherosclerotic diseases, a condition called diabetic cardiomyopathy [6]. Diabetic cardiomyopathy refers to a disease process which affects the myocardium in diabetic patients causing a wide range of structural abnormalities eventually leading to LVH (left ventricular hypertrophy) and diastolic and systolic dysfunction or a combination of these. The functional changes are abnormal diastolic function, compromised left ventricular systolic function, reduced ventricular elasticity and heart failure [7].

The treatment aspect for diabetic cardiomyopathy has to be multifactorial targeting hyperglycemia, hyperlipidaemia and associated cardiovascular risk simultaneously. The current therapy includes the use of sulfonyl ureas/insulin/ thiazolidenediones and beta blocker/ACE (angiotensin converting enzyme) inhibitors/Angiotensin II receptor antagonist/ calcium channel blockers/ statins [8]. In view of this there is a need for precise therapeutics which targets both the objectives. Guggul (Commiphora mukul (Stocks) Hook) (family Burseraceae) has been used to treat various diseases [9] such as inflammation $[10,11]$, hyperlipidemia $[12,13]$, and diabetes [14]. It has been demonstrated to provide cardiovascular benefit by showing cardioprotective effect $[15,16]$. Thus it could possibly target all the aforementioned objectives simultaneously. So far the effect of C. mukul has not been explored for the treatment of diabetic cardiomyopathy. Hence, the present study was undertaken to study the effect of the ethyl acetate extract of C. mukul in the treatment of diabetic cardiomyopathy. 


\section{MATERIALS AND METHODS}

Glucose assay kit, Triglyceride assay kit, Rat Creatinine Kinase MB isoenzyme (CKMB) assay kit and Lactate dehydrogenase (LDH) assay kit were obtained from Transasia Bio-Medicals Ltd. Mumbai. Streptozotocin (STZ) (Sisco Research Laboratories, Mumbai, India) was used for induction of diabetes.

\section{Plant Materials}

The gum resin of C. mukul was collected from local market in Mumbai. The collected plant material was identified and their authenticity was confirmed at Ramnarain Ruia College by Dr. Ganesh Iyer. The extract of the plant was obtained by using the Soxhlet extraction method. Gum resin was crushed and defatted using petroleum ether followed by extraction using ethyl acetate as solvent. This extract of C. mukul was quantified in terms of guggulsterones using HPTLC (High performance thin layer chromatography) [17] (DEGASA ProQuant).

Aluminum plates precoated with silica gel as the stationary phase were developed using toluene: acetone $(9: 1)$ as the mobile phase. A stock solution of the extract and the reference standard was used to estimate the quantity of guggulsterones in the ethyl acetate extract. The densitograms were quantified at $260 \mathrm{~nm}$.

\section{Animals}

Wistar rats weighing between 180-200 g were obtained from Haffkine Biopharma, Mumbai. Animal use in this study was approved by the Institutional Animal Ethics committee (IAEC) (Protocol no. CPCSEA/IAEC/SPTM/P-27/2012). They were housed in polycarbonate cages at room temperature $\left(25 \pm 2{ }^{\circ} \mathrm{C}\right)$ and humidity $(75 \pm 5 \%)$ with $12: 12 \mathrm{~h}$ lightdark cycle. Drinking water and feed were available to animals ad libitum. Acclimatization period of one week was given to the animals before starting the experiment.

\section{Experimental Design}

Animals were divided into four groups of six animals each. Group 1 was treated with the vehicle [CMC, (carboxymethyl cellulose suspension), 1\%], group 2 was diabetic group, group 3 was given only the extract ( $400 \mathrm{mg} / \mathrm{kg}$, p.o.) [18] and group 4 was diabetic animals treated with the extract $(400 \mathrm{mg} / \mathrm{kg}$, p.o.). Diabetes was induced by single intraperitonial injection (i.p.) of STZ $(45 \mathrm{mg} / \mathrm{kg})$ dissolved in citrate buffer ( $\mathrm{pH} 4.5)[19,20]$. The diabetic condition was assessed by measuring the blood glucose concentration $72 \mathrm{~h}$ after STZ injection. The rats with blood glucose levels above $250 \mathrm{mg} / \mathrm{dL}$ were selected for the study (Group 2 and 4). The treatment was started after $3^{\text {rd }}$ day of STZ injection to rats. The protocol was followed for a period of eight weeks. On the fourth, sixth and eighth week blood samples were collected from all the animals for biochemical estimation. After the completion of eight weeks, the body weight of each animal in all groups was recorded and the animals were hemodynamically assessed and sacrificed.

The hearts were collected, labelled and stored. The specimens were fixed in $10 \%$ neutral buffered formaldehyde at room temperature. Sections of 5-7 $\mu \mathrm{m}$ were cut with a sliding microtome and stained with haematoxylin and eosin. The morphological differences observed in the slides were evaluated in each group, the mean scores were calculated.

\section{Biochemical Estimation}

Estimation of glucose, triglycerides, CKMB and LDH was done in rat serum as per the manufacturer's instructions in the respective kits on $4^{\text {th }}, 6^{\text {th }}$ and $8^{\text {th }}$ week.

\section{Hemodynamic Assessments}

On last day of the study, electrocardiogram (ECG) (QT, RR, QTc (corrected QT) intervals and heart rate HR), LVEDP (left ventricular end diastolic pressure), mean arterial blood pressure, LVSP (left ventricular systolic pressure), $\mathrm{dp} / \mathrm{dt}$ max (maximum change in ventricular contractility), $\mathrm{dp} / \mathrm{dt}$ min (minimum change in ventricular contractility) were estimated in all the animals using the Iworks data recording system.

\section{Statistical Analysis}

The differences among experimental and control groups were determined using the graph pad Prism software for Windows. Comparisons among different groups were performed by analysis of variance using one way ANOVA test followed by Bonferroni test. $\mathrm{P}<0.05$ was taken as statistically significant.

\section{RESULTS}

As shown in Table 1, the plasma glucose and triglyceride levels of diabetic animals were significantly higher as compared to normal animals, indicating induction of diabetes. Treatment with the extract lowered these levels as compared to diabetic animals whereas the extract alone did not have any significant effect.

The CKMB and LDH levels in diabetic animals started rising 4 weeks after induction of diabetes and were significantly increased on the $6^{\text {th }}$ and $8^{\text {th }}$ week when compared to normal animals. The treatment with extract prevented the increase in the CKMB levels and lowered the LDH levels.

Table 2 shows the effect of extract on the hemodynamic parameters. The diabetic animals showed a significant increase in the QT, RR, and QTc intervals and corresponding decrease in the heart rate. The LVEDP, mean arterial blood pressure, and contractility index were significantly increased whereas the LVSP, dp/dt max, and dp/dt min, were significantly reduced in diabetic animals. The treated animals show a reverse effect on all these parameters wherein there was a significant reduction in the QT, RR, and QTc intervals and corresponding increase in the heart rate. The LVEDP, mean arterial blood pressure, and contractility index were significantly reduced whereas the LVSP, dp/dt max, and dp/dt min were significantly increased in diabetic animals treated with the extract.

The histopathological studies revealed a moderate change in the myocardium of diabetic animals which was not detected in the treated animals as shown in Table $\mathbf{3}$ and Fig. (1). 
Table 1. Effect of ethyl acetate extract on biochemical parameters.

\begin{tabular}{|c|c|c|c|c|}
\hline Parameters & Group I & Group II & Group III & Group IV \\
\hline \multicolumn{5}{|c|}{ Plasma Glucose (mg/dL) } \\
\hline 6 Weeks & $99.5 \pm 19.7$ & $264.9 \pm 10.1 * * *$ & $100.5 \pm 1.3$ & $104.1 \pm 2.5^{\ldots \#}$ \\
\hline \multicolumn{5}{|c|}{ Plasma Triglycerides (mg/dL) } \\
\hline 4 Weeks & $50.7 \pm 9.3$ & $143.5 \pm 11.3^{* * *}$ & $54.1 \pm 25.9$ & $93.1 \pm 24.8^{\# \#}$ \\
\hline 6 Weeks & $96.1 \pm 12.4$ & $179.0 \pm 12.0 * * *$ & $74.0 \pm 21.7$ & $85.9 \pm 11.1^{\# \#}$ \\
\hline 4 Weeks & $263.2 \pm 116.8$ & $272.9 \pm 44.6$ & $254.3 \pm 43.9$ & $171.7 \pm 19.5^{*}$ \\
\hline 6 Weeks & $196.0 \pm 9.7$ & $326.2 \pm 50.2 * * *$ & $232.8 \pm 46.3$ & $162.5 \pm 25.4^{\# \# \#}$ \\
\hline 8 Weeks & $194.9 \pm 10.3$ & $346.4 \pm 48.6^{* * *}$ & $228.9 \pm 33.6$ & $143.7 \pm 22.0^{\ldots \# \#}$ \\
\hline \multicolumn{5}{|c|}{ LDH(IU/L) } \\
\hline 4 Weeks & $191.7 \pm 32.7$ & $263.2 \pm 39.6^{* *}$ & $219.9 \pm 20.6$ & $300.6 \pm 48.6$ \\
\hline 6 Weeks & $175.1 \pm 24.7$ & $265.4 \pm 47.4 * * *$ & $214.3 \pm 14.1$ & $235.8 \pm 11.6$ \\
\hline
\end{tabular}

Notes: Each values represent Mean \pm S.E.M. for the number of animals utilized during experiment. $* \mathrm{P}<0.05$ vs normal group, $* * \mathrm{P}<0.01$ vs normal group, $* * * \mathrm{P}<0.001 \mathrm{vs}$ normal group, and ${ }^{\#} \mathrm{P}<0.001$ vs diabetic control.

Table 2. Effect of the ethyl acetate extract on hemodynamic measurements.

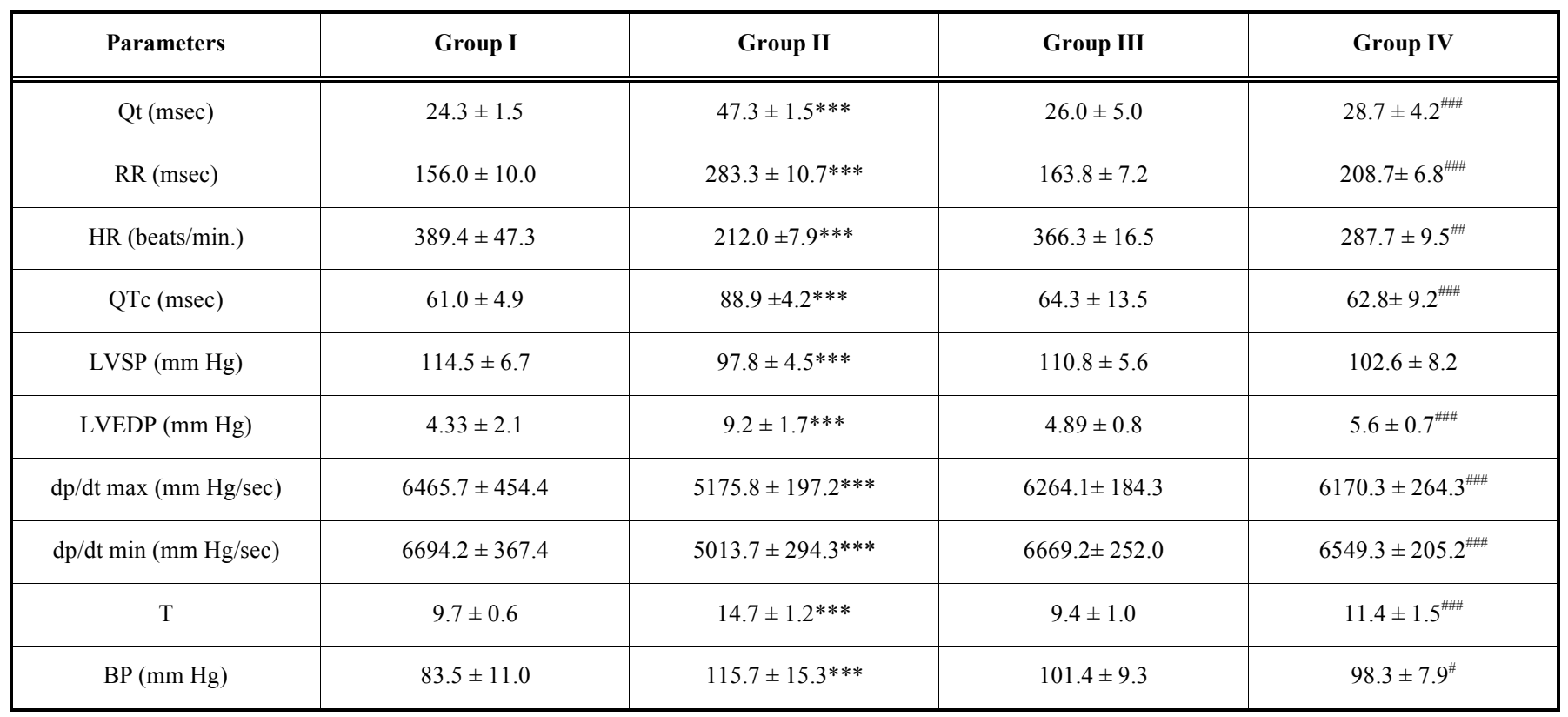

Notes: Each values represent Mean \pm S.E.M. for the number of animals utilized during experiment. $* * * \mathrm{P}<0.001$ vs normal group and ${ }^{\# \#} \mathrm{P}<0.01$ vs diabetic control, ${ }^{\# \#} \mathrm{P}<0.001$ vs diabetic control, ${ }^{\#} \mathrm{P}<0.05$ vs diabetic control. 
Table 3. Summary of histopathological findings of the heart on the $8^{\text {th }}$ week.

\begin{tabular}{|c|c|c|c|c|}
\hline Congestion \& hemorrhages in epicardium \& myocardium & NAD & + & + & NAD \\
\hline $\begin{array}{l}\text { Loss of nucleus and necrotic changes in cardiac fibers with coagulative changes in } \\
\text { muscle bundles }\end{array}$ & NAD & ++ & NAD & NAD \\
\hline
\end{tabular}

Notes: $\mathrm{NAD}=$ No Abnormality Detected. + Minimal changes, ++ Mild changes, +++ Moderate changes.

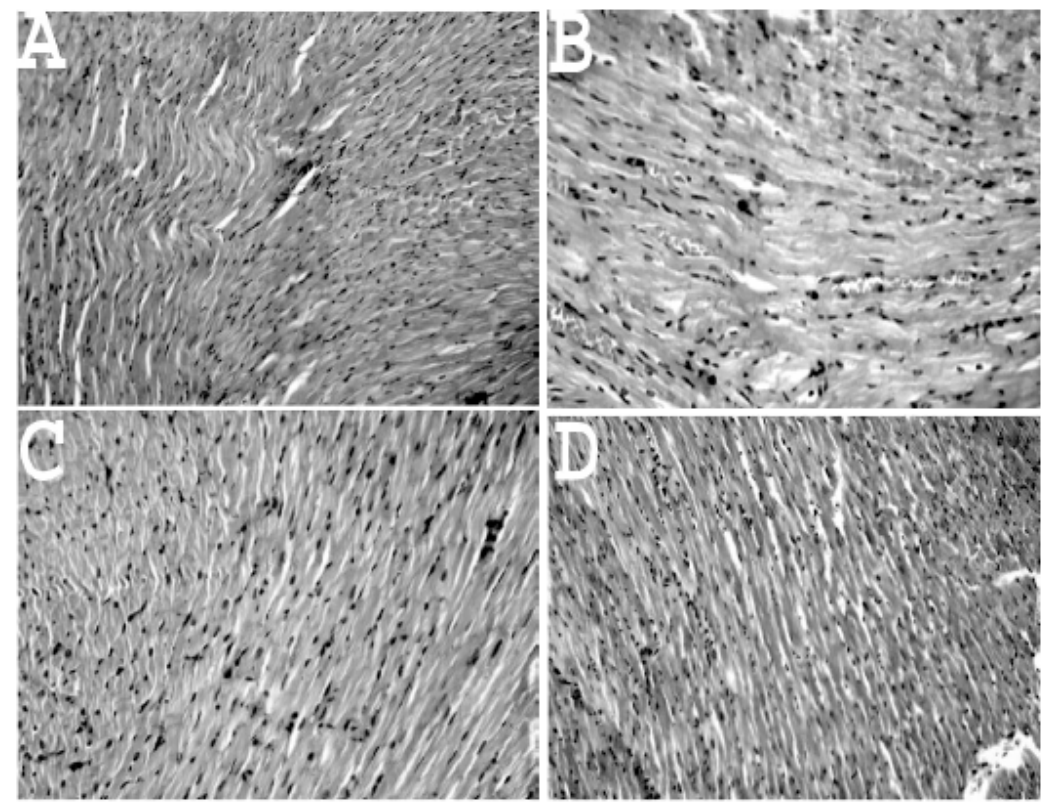

Fig. (1). Photomicrograph of sections of left ventricles from rats stained with H \& E. left ventricle microscopic image of (A) normal rats (B) diabetic rats (C) normal rats treated with EACM (D) diabetic rats treated with EACM (microscopic examination under x200 light microscopy).

\section{DISCUSSION}

Diabetes mellitus is a very common and serious metabolic disease which is linked to several long term complications such nephropathy, neuropathy, retinopathy and cardiovascular complications. Recent experimental studies have shown that a specific cardiomyopathy can be the causative factor for producing mortality in diabetes. Diabetic cardiomyopathy found to be most prevalent, the early stages being hyperglycemia, increased circulating free fatty acids, insulin resistance, altered $\mathrm{Ca}^{2+}$ homeostasis and endothelial dysfunction. The middle stage shows significant change in systolic and diastolic function while the late stage is characterized by abnormal systolic and diastolic function [7].

The i.p. injection of STZ generates oxidative stress in the pancreas, causing a significant increase in the fasting blood glucose levels when compared to normal rats. The present study show decreased glucose levels in the treatment group when compared with the diabetic group, once again proving the antihyperglycemic activity of the extract. Studies have shown that treatment with STZ causes derangement of lipid profile. Alteration in lipid metabolism can also alter heart function by modifying the structure of cardiac plasma and subcellular membranes [20]. The present study showed an increase in the triglyceride levels of diabetic animals. These were found to be lowered after oral administration of the extract, thus guggul can effectively prevent hypertriglyceridemia resulting due to diabetic dyslipidemia.

There are very few reports about the anti hypertensive effect of Guggul extract. One clinical study [21] has the shown Guggul to have antihypertensive effect which might be due to its hypolipidaemic activity which in turn alters impaired endothelial function and vascular tone.

For better specificity of cardiac injury, measurement of LDH and CKMB are necessary, since a non-specific increase of total $\mathrm{LDH}$ and $\mathrm{CK}-\mathrm{MB}$ in serum occur following tissue damage [22]. The CK-MB and LDH values were found to be same in all the groups at 4 weeks of treatment but the increased levels in diabetic animals after 6 and 8 weeks suggest cardiac muscle impairment, whereas oral administration of ethyl acetate extract of guggul was effective in preventing cardiac muscle degeneration as indicated by the normal values of the aforementioned enzymes. 
There are reports where STZ-induced diabetes have shown long-term effects on the ECG, systolic performance, rate of change of ventricular pressure, mean blood pressure and QT values in rats $[20,22,23]$. The present study showed increase in mean blood pressure in STZ injected rats whereas the other groups showed the normal mean blood pressure. The diabetic group showed marked decrease in $+\mathrm{dP} / \mathrm{dt}$, $\mathrm{dP} / \mathrm{dt}$ and increase in mean LVDEP when compared to normal group indicating diabetic cardiomyopathy. Oral administration of ethyl acetate extract of gum resin maintained normal $+\mathrm{dP} / \mathrm{dt}$, $-\mathrm{dP} / \mathrm{dt}$ and mean LVDEP.

The QT interval represents the time for both ventricular depolarization and repolarization to occur, and therefore roughly estimates the duration of an average ventricular action potential and prolongation of this QT intervals can be a diagnostic susceptibility in repolarization abnormalities specifically arrythmia. The present study showed significant increase in the QT interval and in the diabetic control group. The oral administration of the ethyl acetate extract of the gum resin significantly reduced the duration of QT interval. Reduction in the heart rate is indicative of myocardial dysfunction, which is observed in the diabetic animals and is effectively reversed after treatment with the extract.

An increase in LVEDP, contractility index $(\tau)$ and blood pressure and corresponding decrease in the $\mathrm{dp} / \mathrm{dt} \max , \mathrm{dp} / \mathrm{dt}$ min are all indicative of impaired contractility of the myocardium which is observed in the diabetic animals and is reversed in the treated group, suggesting role of guggul extract in preventing myocardial dysfunction.

The present study showed mild degenerative changes, loss of nucleus and necrotic changes in the cardiac fibers, cellular swelling in the myocardium fibers in the diabetic control whereas the treatment group showed minimal changes.

The data suggest that the ethyl acetate extract of C. mu$\mathrm{kul}$ is effective in preventing diabetes induced myocardial dysfunction when administered orally for a period of 8 weeks.

\section{CONCLUSION}

Guggul is reported to lower the STZ induced diabetic oxidative stress in the myocardium thereby protecting it from dysfunction [24]. Guggul has been reported to be a Farnesoid $\mathrm{X}$ receptor antagonist (FXR). FXR is a bile-acid-activated receptor regulating the expression/function of key genes in lipid and glucose metabolism [25] and bile acid homeostasis. It also plays a vital role in cardioprotection through various mechanisms such as regulation of endothelial nitric oxide synthase (eNOS), angiotensin type 2 receptor expression [26, 27]. Moreover, guggulipids also have both PPAR- $\alpha$ and PPAR- $\gamma$ agonistic activity [28], thus exerting a dual effect modulating glucose and lipid metabolism, which is further responsible for the cardioprotective activity. Thus, taking into consideration these molecular mechanisms of guggul extract, it could be used to prevent the diabetic cardiomyopathy as is observed in the present study. However, further validation of these claims and clinical trials need to be initiated to proclaim the use of guggul in treating diabetic cardiomyopathy.
ABBREVIATIONS
$\mathrm{ACE}=$ Angiotensin converting enzyme
$\mathrm{CAD}=$ Coronary artery disease
$\mathrm{CKMB}=$ Creatinine Kinase MB isoenzyme
$\mathrm{CMC}=$ Carboxymethyl cellulose
$\mathrm{EACM}=$ Ethyl acetate extract of Commiphora mukul
$\mathrm{ECG}=$ Electrocardiogram
eNOS $=$ Endothelial nitric oxide synthase
FXR $=$ Farnesoid X receptor
$\mathrm{HPTLC}=$ High performance thin layer chromatography
$\mathrm{HR}=$ Heart rate
$\mathrm{IAEC}=$ Institutional Animal Ethics committee
$\mathrm{IDF}=$ International Diabetes Federation
$\mathrm{LDH}=$ Lactate dehydrogenase
$\mathrm{LVH}=$ Left ventricular hypertrophy
LVEDP $=$ Left ventricular end diastolic pressure
$\mathrm{QT}=$ QT interval in the ECG wave (P-Q-R-S-T)
QTc $=$ Corrected QT
RR $=$ RR interval in two ECG waves
$\mathrm{STZ}=$ Streptozotocin
$\mathrm{T} 1 \mathrm{D}=$ Type I diabetes
$\mathrm{T} 2 \mathrm{D}=$ Type II diabetes

\section{CONFLICT OF INTEREST}

The authors confirm that this article content has no conflict of interest.

\section{ACKNOWLEDGEMENTS}

We are thankful to Dr. Chandrashekhar Mote at Innovet Diagnostic Laboratory, Pune for helping us with histopathological studies and Dr. Lokesh Bhatt, Assistant Professor, Bhanuben Nanavati College of Pharmacy, Mumbai University for rendering his valuable suggestions. The authors also thank SVKM's NMIMS for funding the project.

\section{PATIENT'S CONSENT}

Declared none.

\section{REFERENCES}

[1] Gupta, R. Diabetes in India: Current Status. Express Healthcare: India Aug 2008.

[2] Huizinga, M.M.; Rothman, R.L. Addressing the diabetes pandemic: a comprehensive approach. Ind. J. Med. Res., 2006, 124, 481-484 f.

[3] Drucker, D.J. Enhancing incretin action for the treatment of type 2 diabetes. Diabetes. Care, 2003, 26, 2929-2940.

[4] Panunti, B.; Jawa, A.; Fonseca, V. Mechanisms and therapeutic targets in type 2 diabetes mellitus. Drug Discov. Today: Dis. Mech., 2004, 1(2), 151-157.

[5] Wang, J.; Song, Ye.; Wang, Q.; Kralik, P.M.; Epstein, P.N. Causes and characteristics of diabetic cardiomyopathy. Rev. Diabet. Stud., 2006, 3(3), 108-117. 
[6] Sihem Boudina, E.; Dale, A. Diabetic cardiomyopathy revisited. Circulation, 2007, 115, 3213-3223.

[7] Tiwari, A.K.; Rao, M.J. Diabetes mellitus and multiple therapeutic approaches of phytochemicals: Present status and future prospects. Curr. Sci., 2002, 83(1), 30-38.

[8] Hayat, S.A.; Patel, B.; Khattar, R.S.; Malik, R.A. Diabetic cardiomyopathy: mechanisms, diagnosis and treatment. Clin. Sci., 2004, 107, 539-557.

[9] Shen, T.; Li, G.H.; Wang, X.N.; Lou, H.X. The genus Commiphora: a review of its traditional uses, phytochemistry and pharmacology. J. Ethnopharmcol., 2012, 142(2), 319-330.

[10] Cheon, J.H.; Kim, J.S.; Kim, J.M.; Kim, N.; Jung, H.C.; Song, I.S. Plant sterol guggulsterone inhibits nuclear factor-kappaB signaling in intestinal epithelial cells by blocking IkappaB kinase and ameliorates acute murine colitis. Inflamm. Bowel Dis., 2006, 12, 11521161.

[11] Duwiejua, M.; Zeitlin, I.J.; Waterman. P.G.; Chapman, J.; Mhango, G.J.; Provan, G.J. Anti-inflammatory activity of resins from some species of the plant family Burseraceae. Planta Med., 1993, 59, 1216.

[12] Chander, R.; Khanna, A.K.; Kapoor, N.K. Lipid lowering activity of guggulsterone from Commiphora mukul in hyperlipaemic rats. Phytother. Res., 1996, 10, 508-511.

[13] Urizar, N.L.; Liverman, A.B.; Dodds, D.T.; Silva, F.V.; Ordentlich, P.; Yan, Y.; Gonzalez, F.J.; Heyman, R.A.; Mangelsdorf, D.J.; Moore, D.D. A natural product that lowers cholesterol as an antagonist ligand for FXR. Science, 2002, 296, 1703-1706.

[14] Bellamkonda, R.; Rasineni, K.; Singareddy, S.R.; Kasetti, R.B.; Pasurla, R.; Chippada, A.R.; Desireddy, S. Antihyperglycemic and antioxidant activities of alcoholic extract of Commiphora mukul gum resin in streptozotocin induced diabetic rats. Pathophysiology, 2011, 18, 255-261.

[15] Deng, R. Therapeutic effects of guggul and its constituent guggulsterone: cardiovascular benefits. Cardiovasc. Drug Rev., 2007, 25(4), 375-390.

[16] Ojha, S.; Bhatia, J.; Arora, S.; Golechha, M.; Kumari, S.; Arya, D.S. Cardioprotective effects of Commiphora mukul against isoprenaline-induced cardiotoxicity: a biochemical and histopathological evaluation. J. Environ. Biol., 2011, 32(6), 731-738.

[17] Agarwal, S.K.; Tajuddin, S.; Mohammad, S.; Kumar, S.; Khanna, A.K.; Ramesh, C. in inventors; Council of Scientific and industrial research, in -assignee. Process for the isolation of Z-and Egugulsterones from aerial branches of Commiphora wightii, US Patent 6086889A, 2000.
[18] Ojha, S.K.; Nandave, M.; Arora, S.; Mehra, R.D.; Joshi, S.; Narang, R.; Arya, D.S. Effect of Commiphora mukul extract on cardiac dysfunction and ventricular function in isoproterenol-induced myocardial infarction. Ind. J. Exper. Biol., 2008, 46, 646-652.

[19] Bar-On, H.; Roheim, P.S.; Eder, H.A. Hyperlipoproteinemia in streptozotocin-treated rats. Diabetes, 1976, 25(6), 509-515.

[20] Akula, A. Biochemical, histological and echocardiographic changes during experimental cardiomyopathy in STZ-induced diabetic rats. Pharmacol. Res., 2003, 48(5), 429-35.

[21] Panneerselvam, J.; Sambandam, G.; Nalini, N. Single- or doubleblind treatment with Balsamodendron mukul and nifedipine in hypertensive patients . J. Clin. Hyperten., 2005, 7(6), 340-345.

[22] Upaganlawar, A.; Balaraman, R. Effect of vitamin E and green tea on hemodynamic, electrocardiographic and some biochemical alterations in experimentally induced myocardial infarction in rats. $J$. Young Pharm., 2011, 3(4), 297-303.

[23] D'Amico, M. High glucose induces ventricular instability and increases vasomotor tone in rats. Diabetologia, 2001, 44(4), 464-70.

[24] Ramesh, B.; Karuna, R.; Reddy, S.S.; Haritha, K.; Sai, M.D.; Sasis, B.R.B.; Saralakumari, D. Effect of Commiphora mukul gum resin on hepatic marker enzymes, lipid peroxidation and antioxidants status in pancreas and heart of streptozotocin induced diabetic rats. Asian Pac. J. Trop. Biomed., 2012, 2(11), 895-900.

[25] Cui, J.; Huang, L.; Zhao, A.; Lew, J.L.; Yu, J.; Sahoo, S.; Meinke, P.T.; Royo, I.; Pelaez, F.; Wright, S.D. Guggulsterone is a farnesoid $\mathrm{X}$ receptor antagonist in coactivator association assays but acts to enhance transcription of bile salt export pump. J. Biol. Chem., 2003, 278, 10214-10220.

[26] Zhang, Q.; He, F.; Kuruba, R.; Gao, X.; Wilson, A.; Li, J.; Billiar, T.R.; Pitt, B.R.; Xie, W.; Li, S. FXR-mediated regulation of angiotensin type 2 receptor expression in vascular smooth muscle cells. Cardiovasc. Res., 2008, 77(3), 560-569.

[27] Li, J.; Wilson, A.; Kuruba, R.; Zhang, Q.; Gao, X.; He, F.; LiMing, Z.; Pitt, B.R.; Xie, W.; Li, S. FXR-mediated regulation of eNOS expression in vascular endothelial cells. Cardiovasc. Res., 2008, 77(1), 169-177.

[28] Cornick, C.L.; Strongitharm, B.H.; Sassano, G.; Rawlin, C.; Mayes, A.E.; Joseph, A.N.; O'Dord, J.; Stocker, C.; Wargent, E.; Cawthorne, M.A.; Brown, A.L.; Arch, J.R. Identification of a novel agonist of peroxisome proliferatoractivated receptors $\alpha$ and $\gamma$ that may contribute to the anti-diabetic activity of guggulipid in Lepob/Lepob mice. J. Nutr. Biochem., 2009, 20(10), 806-815.

(c) Barve and Bhonsle; Licensee Bentham Open.

This is an open access article licensed under the terms of the Creative Commons Attribution Non-Commercial License (http://creativecommons.org/licenses/by-nc/3.0/) which permits unrestricted, non-commercial use, distribution and reproduction in any medium, provided the work is properly cited. 